\title{
Agendas de investigación indígena y decolonialidad
}

\author{
Agendas for indigenous research and decoloniality
}

\author{
Anderson Rocha-Buelvas* - Rodrigo Ruíz-Lurduy**
}

\begin{abstract}
Resumen: El artículo es un aporte reflexivo al debate de la investigación decolonial para pueblos indígenas en el campo académico. Se presentan algunas propuestas teóricas recientes en torno al paradigma de investigación decolonial, las cuales rastrean los caminos posibles para la construcción de una postura desde y para la subalternidad que permita la incorporación metodológica, ontológica, ética y praxiológica de la ciencia y el conocimiento ancestral en el campo académico. El documento concluye con una reflexión en torno a las ventajas de involucrar el saber indígena en la construcción metodológica y epistemológica del campo académico, donde la decolonialidad es el denuedo, el paso obligado y la transición pendiente hacia la investigación indígena.
\end{abstract}

Palabras clave: Conocimiento tradicional; Colonialismo; Investigación cultural; Poblaciones indígenas; paradigma decolonial

\begin{abstract}
The article is a thoughtful contribution to the debate decolonial research for indigenous peoples in the academic field. Some recent theoretical proposals around the paradigm of indigenous research presented, which track the possible paths for building a stance from and subservience to allow methodological, ontological, ethical and praxiological incorporation of science and ancestral knowledge in the academic field. The paper concludes with a reflection on the advantages of involving indigenous knowledge in the methodological y epistemological construction of the academic field, where decoloniality is the boldness, the obligatory step and the pending transition towards indigenous research.
\end{abstract}

Key words: Traditional knowledge; Colonialism; Cultural research; Indigenous people

Recibido: 1 agosto 2017

Aceptado: 14 diciembre 2017

*Colombo-Venezolano. Autor principal. Candidato a Doctor en Salud Pública, Universidad Nacional de Colombia. E-mail: rochabuelvas@gmail.com

**Colombiano. Co-autor. Candidato a Doctor en Antropología Social. Docente, Fundación Universitaria del Área Andina. E-mail: rruiz13@areandina.edu.co 


\section{La colonialidad y la subalternidad indígena}

En las últimas décadas el paradigma decolonial, como ruta del pensamiento indígena en América Latina y del pensamiento nativo en países angloparlantes, se ha impuesto en la academia como contrapeso a la colonialidad y sus dimensiones ${ }^{2}$. Desde la república hasta nuestros días se ha consolidado la colonialidad como un arquetipo de estratificación socioracial, donde existen los -blancos-y las otras -tipologías raciales- (Gesco, 2012). A finales del siglo XX, el capitalismo como artífice de la colonialidad se ha empoderado más. Una de las estrategias ha sido el discurso de la interculturalidad pensado desde el mestizaje como un proyecto dominador-global, cuyos desarrollos educativos y socio-históricos multiculturales (Walsh, 2007) anulan a la otredad/sujeto-subalterno ${ }^{3}$-indígena. Este colonialismo académico también impone la aceptación del binomio mando-obediencia, y en contraparte una necesidad de resistencia y negociación permanente (Gramsci, 1975).

La decolonialidad del poder como la disolución de las estructuras de dominación y explotación, y el desmantelamiento de los dispositivos ideológicos de la colonialidad del poder $^{4}$, se inserta hoy en el conocimiento académico como una propuesta epistémica, teórica y metodológica que pretende superar esta matriz histórica (Gesco, 2012), dicho de otra forma, resiste a la modernidad ${ }^{5}$ (Quijano, 2007). Actualmente los pueblos indígenas como otros grupos subalternos se enfrentan al colonialismo ${ }^{6}$ global encarnado en la interseccionalidad de jerarquías globales múltiples y sus heterogéneas formas de dominación y explotación: sexual, política, económica, espiritual, linguiística y racial (Grosfoguel, 2006) impuestas desde la conquista de América (Escobar, 1998). Esta matriz ignora y subestima los intereses y la cosmovisión de los pueblos originarios, en cuanto a homogenizado a la sociedad; esto a través del control social, las instituciones, los Estados y sus constituciones, la industrialización, el desigual ejercicio de la autonomía mediante las clases sociales y la extinción de las 'otras' tradiciones sin cuestionamiento alguno (Bauman, 1998 \& Arendt, 2004).

Por consiguiente, la colonialidad del ser y del saber se configuran como las principales fuentes constitutivas de esta matriz (Gesco, 2012) que el pensamiento decolonial reconoce y rechaza. La colonialidad del ser niega el ser del otro, por tanto, es una negación ontológica, una herida colonial (Maldonado\&Torres, 2007) y el despojo relativo de la calidad subjetiva por medio de la subordinación (Gramsci, 1975) deotras ontologías. Mientras la colonialidad del saber o del conocimiento, es la racionalidad técnico-científica

\footnotetext{
${ }^{2}$ La triple dimensión está constituida por el racismo, el eurocentrismo epistémico y la occidentalización violenta de los estilos de vida.

${ }^{3}$ Instrumento analítico, passepartout del lenguaje intelectual y académico y recurso verbal del discurso político progresista.

${ }^{4}$ Patrón de dominación global que se constituye como el intrínseco lado oculto de la modernidad.

${ }^{5}$ Puede ser considerada una categoría analítica referida al movimiento socio-histórico de la Ilustración, que apela por la autonomía del hombre como ejercicio de su propia voluntad, es decir, la racionalidad y la lógica como caminos para conseguir la autonomía.

${ }^{6}$ Es una estructura de dominación con autoridad política en otra jurisdicción territorial. También le denomina sistema mundo euronorteamericano capitalista/ patriarcal/ moderno/ colonial.
} 
que se presenta como una narrativa universal que pretende hacer evidente quién y desde donde se produce ese conocimiento, generando una descalificación epistémica del otro (Lander, 2000). El conocimiento decolonial y su lucha a través de la movilización social y su incipiente incorporación a la academia se oponen a la pureza epistémica donde la ciencia es un instrumento de dominación situado en el punto cero de la observación, desechando otras perspectivas y metafísicas mediante la hegemonía de la raza, los saberes modernos, las tecnologías de gobierno y la institucionalización (Castro \& Gómez, 2004). El conocimiento decolonial advierte que ser partícipes de lo que Foucalt (1993) llamaba prácticas de estatalización, medicalización, subjetivación y cientifización, incluso siendo un sujeto subalterno, puede hacernos cómplices de la violencia epistémica (Castro et al, 2007).

\section{La academia como instrumento dominador}

Es claro que la decolonialidad no solo representa un concepto sino representa la experiencia de reconocer al otro (Grosfoguel, 2007), es una actitud. Por esta razón, el primer paso necesario para hablar de conocimiento indígena, es revelar que las categorías "indio" y "nativo" se instalan en situaciones de dominación política, económica y cultural, donde la clasificación étnico-racial del mundo moderno, les arrebata su historicidad y subjetividad como otro 'indígena', atribuyéndoles una identidad subalterna (Wolf, 1987; Ashcroft, 1995; Quijano, 2000; Mignolo, 2007; Mezzadra, 2008). Como bien se sabe los indígenas americanos durante más de 500 años han sido sometidos a un profundo proceso de opresión social-política-económica-cultural, donde la academia ha sido otro vehículo para sus verdugos (Asad, 1973; Stocking, 1974), pues ha afianzado la idea de que el conocimiento proveniente de la subalternidad es inferior. Mientras los aparatos estatales y mercantiles despojan a los indígenas de sus tierras, de su cultura, de su dignidad y de su humanidad (Harper, 1986; Ferro, 2005).

El reto más importante entonces de la decolonialidad y del conocimiento de los pueblos indígenas consiste en darle lugara sus epistemologías en confrontación con el "racismo epistémico" (Trouillot, 2011), ya que la academia es uno de los escenarios más importantes por conquistar. Para ello, es fundamental reconocer que las culturas ancestrales tienen una lógica diferente y en conflicto con la lógica científica eurocéntrica. Esta diferencia radica en que la lógica indígena opera dentro de un sistema de sentido-pensamiento sobre la naturaleza, la cual se sitúa en un"acervo de creencias-saberes y de prácticas rituales que constituyen el cuerpo del saber indígena"(Piñacué, 2014).Por consiguiente, la visión decolonial, considera que el conocimiento de los pueblos indígenas plantea la necesidad deco-razonar con el territorio (Fals Borda, 2009; Escobar, 2014).El distanciamiento entre el conocimiento indígena y el conocimiento disciplinar occidental es una situación dialéctica vigente, que plantea una lucha del movimiento indígena por reivindicar y legitimar su conocimiento en espacios interculturales como las universidades pese a que perturben el orden del lugar de origen (Piñacué, 2014).

La epistemología indígena plantea el examen de la categoría cosmovisión como punto de partida de la disquisición con el mundo occidental, ya que la experiencia existencial e 
histórica de los individuos y colectividades indígenas tienen su propio modo de ver, interpretar y actuar en y sobre el mundo (Hart, 2010). Por lo tanto, para explicar el giro en la relación entre la visión indígena y la academia, es útil entender que, en primer lugar,el pensamiento indígena se instala en los fenómenos de la naturaleza y luego enuncia sus saberes y conocimientos (Piñacué, 2014), contrario al conocimiento occidental que instala el conocimiento a partir de la observación y la objetivación de los fenómenos de la naturaleza y el hombre (Hume, 1967) de una manera fragmentada. En segundo lugar, se debe entender que para los indígenas, la "naturaleza es la única maestra y fuente de sabiduría" (Lame, 2004), es por ello, que la experiencia del territorio-creencia-saber es considerado un principio instituido en la multitud cohesionada, es decir, en el colectivo, ya que el conocimiento ancestral se configura en los antepasados (el pasado es presente y el pasado es futuro porque los jóvenes indígenas retoman el conocimiento de los ancianos).Y en tercer lugar se debe entender que la práctica del pensamiento indígena se configura a escala 'local-global', es decir, las ideas se debaten en un escenario doméstico y se agotan en un escenario multitudinario como los congresos indígenas (Piñacué, 2014). De modo que la construcción intangible del indígena es controlada por los medios culturales siempre permisibles(Lévi-Strauss, 1987), incluso en la academia.

Todo ello indica que la decolonialidad y el conocimiento indígena se vinculan en la filosofía política del materialismo dialectico porque considera que el rol del conocimiento en estas sociedades no divide socialmente el trabajo intelectual y el manual (Engels, 1992), es decir, el papel del que piensa no existe, por tanto, los pensamientos, los conceptos y las ideas de los pueblos indígenas están colmadas de materia. Lucien Lévy-Bruhl,(2003) y luego Lévi-Strauss, (1964) afirmaban que los indígenas no piensan en abstracto como los occidentales porque analizan la coyuntura material concreta y específica (Vasco, 2003). Esto no significa que su epistemología sea el materialismo dialectico, sino que precisamente por su fundamento ontológico, su ciencia se desarrolla en términos de lo concreto, sin separar la cosa de su sentido.

\section{Investigación desde y para pueblos indígenas}

Los estudios culturales tienen dos áreas de conocimiento: los estudios poscoloniales y los de subalternidad (Ashcroft, 1995). Estos podrían considerarse como un vehículo reflexivo dirigido a la inserción del paradigma indígena de investigación como una respuesta más a los procesos de exclusión, dominación e invisibilización de saberes y prácticas. Este paradigma se ha constituido a partir de tres núcleos de investigación: la colonialidad del conocimiento científico (Quijano, 2000); la indigenización (Gray, 2008); y la acción social comunitaria descolonizante y emancipante (Smith, 2008; Gray, 2013), las cuales no han sido bien interpretadas y reconocidas por la academia norteamericana y europea, aun cuando son una demanda epistemológica (Hart, 2010). Hay que aclarar que las 'metodologías indígenas', la 'ciencia nativa' o las 'agendas de investigación indígena' no son diferentes al paradigma indígena de investigación ni son construcciones teóricas de diferentes escuelas de pensamiento, más bien, obedecen a una iniciativa compartida 
transfronteriza de académicos indígenas preocupados por superar el paradigma decolonial (Arévalo \& Robles, 2013).

El paradigma de investigación indígena revaloriza e implementa el saber ancestral/tribal como manifestación ético-política de autodeterminación y justicia social mediante la crítica de la relación saber-poder colonial. Por tanto, a todas luces es una interacción racional, espiritual e intuitiva que, en un sentido holístico y complementario, no aísla ni fragmenta la realidad en partes; por el contrario, privilegia las relaciones interdependientes y complementarias de la realidad (Arévalo \& Robles, 2013).

Resulta importante para la lucha del conocimiento indígena, en primer lugar, que el paradigma de investigación indígena haya tenido sus mayores desarrollos académicos al interior de los países que invadieron y usurparon sus tierras, destruyeron los sistemas políticos, sociales, económicos y culturales de los pueblos originarios y los obligaron a un proceso de dependencia económica y política a occidente (Chilisa, 2012); en segundo lugar, que los procesos de descolonización de la educación y la investigación inicien con la consolidación de las cosmovisiones y perspectivas indígenas con sus prácticas, valores, experiencias y sentidos dado el descredito y sometimiento de estos a un sistema de conocimiento, valores y comportamientos (Arévalo \& Robles, 2013) que ordena al mundo (Smith, 1999) con fines y excesos científicos y comerciales como política recurrente. Y finalmente que la palabra 'investigación' desde el paradigma indígena a pesar de reutilizarse, sea una de las más inapropiadas en el vocabulario, puesto que los métodos de investigación occidental, los consideraron subalternos por aseverar que eran "genéticamente inferiores" y "culturalmente desviados" (Renee, 2007).

Por tanto, es fundamente que, en la lucha del conocimiento indígena, el centro del conocimiento se erija en la ecosofía de la vida o la cosmovisión donde no se establecen relaciones dualistas entre mente/cuerpo, pensamiento/acción y sociedad/naturaleza (Cajigas \& Rotundo, 2007). Los principios de la noción de cosmovisión son inherentes al conocimiento indígena y declaran que i. "El conocimiento es holístico, cíclico, y relacional; ii. De las experiencias individuales dependen las verdades, iii. "Todo está vivo"; iv. "Todas las cosas son iguales", v. "La tierra es sagrada", vi. La relación entre las personas y el mundo espiritual es inseparable, y vii. "Los seres humanos importan menos que el mundo" (Simpson, 2000). De modo que las cosmovisiones indígenas son la razón más importante por la cual se propone la implantación de una metodología descolonizada, donde los indígenas realicen investigación desde los saberes indígenas, sin descartar la participación de investigadores no-indígenas que lo viven y lo comprenden. Desde luego esto requerirá un proceso colectivo y ancestral sobre la necesidad de investigar por los pueblos indígenas y sobre el liderazgo indígena de estas investigaciones en las instituciones, ya que "la investigación científica está implicada en los peores excesos del colonialismo”, por tanto, es la investigación "un importante sitio de la lucha entre los intereses y formas de conocimiento de occidente y los intereses y formas de conocimiento del Otro" (Smith, 1999). 
La aceptación de las nociones de alteridad, representación, discurso, identidad, saber-poder en el mundo actual (Sikes, 2006) son una oportunidad para que la investigación indígena asuma un proceso de decolonización que se encargue de la recuperación de la cultura, la historia, la identidad y la lengua que han sido distorsionados, así como del duelo, del dreaming $^{7}$, del compromiso y la acción o la lucha por la ética, la justicia social y la propia determinación. Lo anterior con el objeto de consolidar una "autoestima social" a partir del saber cultural pero también a partir de jurisprudencias, políticas públicas, y por supuesto protocolos de protección del conocimiento ancestral y su cosmovisión (Laenui, 2000; Chilisa, 2012), es decir, un paradigma de investigación indígena requiere una postura política en defensa de los derechos colectivos y una posición que repiense su forma de decolonizar, ya que el "colonialismo depende de los modelos, estructuras, epistemologías y enfoques occidentales" (Kuokkanen, 2000).En resumidas cuentas el reto del paradigma de investigación indígena será tomar control sobre las vidas y territorios a través de la generación de procesos de conocimiento que respeten sus costumbres, honren sus ritos y reconozcan sus cosmovisiones como forma concreta de autodeterminación, existencia y supervivencia (Martin, 2003).

De manera que el paradigma de investigación indígena no puede ser confundido con la ciencia nativa. La ciencia nativa es inseparable a la cosmovisión indígena porque se refiere a los aprendizajes milenarios sistematizados y expresados en la forma de pensar, actuar y percibir del indígena. Esta integra la espiritualidad, el conocimiento humano basado en la cosmología, la perpetuación de los procesos naturales del mundo; el respeto por los lugares, plantas, animales y fenómenos naturales; la interdependencia; los ancianos guardianes del conocimiento; en resumen, los principios de la noción de cosmovisión, cuyas actuaciones en el mundo son a través del ritual, la ceremonia y los sueños como puerta a la creatividad y el conocimiento. En tanto que el paradigma indígena de investigación si bien yace en la ciencia nativa, surge recientemente como modelo de conocimiento en las universidades y por causa de la exclusión. Este implica tecnologías, comunidad y espiritualidad, pero también el concepto, la lógica y la racionalidad empírica (Cajete, 1999), por tanto, lo constituyen una ontología, una epistemología, una metodología y una axiología (Wilson, 2008). El paradigma indígena de investigación se construye en diálogo con la ciencia occidental, pero se origina en la ciencia ancestral (Pannikar, 1994), ya que requiere interlocutar con los terminos occidentales para constituir metodologías originalmente indígenas y decoloniales (Kovach, 2010).

Es importante mencionar que las ontologías dentro del paradigma indígena habitan en el contexto de las cosmovisiones de cada nación o pueblo indígena; esta relacionalidad define la 'totalidad' como unidad del todo, el todo que existe, lo material como lo inmaterial (Arévalo\&Robles, 2013), es decir, la esfera espiritual y física, cuya materialización ceremonial y ritual posee un anclaje histórico (Leyva, 2008). Es por ello que del mundo amerindio surge el 'Buen Vivir' como una de esas concepciones de relacionalidad que lleva

${ }^{7}$ El dreaming es referido al Dreamtime asociado a los seres ancestrales que se movilizan por la tierra y se conectan con sus nietos, por tanto, permanece en los valores culturales, los conocimientos y los sistemas de creencias. 
su ontología al plano de la interculturalidad y la decolonialidad (Acosta, 2009) como principio central de la filosofía de existencia indígena que orientan el pensamiento del bien estar colectivo, no desde la obtención del poder sino desde la necesidad de un vivir bien para todos (Walsh, 2009)

Acá es necesario recordar los aportes que desde el giro ontológico ha hecho la antropología para acercarse a las epistemologías indígenas; radicalizando su postura respecto a la reflexividad, la conceptualización y la experimentación en la disciplina (Viveiros de Castro, 2004). Esto lo que indica es un llamado a las ciencias sociales para resolver el reto de ver las cosas de una forma distinta, ¿cómo, en primer lugar, es posible ubicarse en la alteridad?; y segundo, ¿cómo neutralizar o manejar el peligro del eurocentrismo? La propuesta en sí, es indagar desde la alteridad lo que las cosas son en sí para los indígenas, no sólo captar el punto de vista del nativo, sino estar en el punto de vista del nativo. Para ello se parte de radicalizar la postura reflexiva, no se trata sólo de estar atento a la forma en que se hace etnografía, sino que se rehúsa a cualquier contenido previo que no surja de las cosas (Wagner, 1981). Esto tiene un efecto en el trabajo de conceptualización del conocimiento, pues implica generar re-conceptualizaciones sobre lo que el investigador piensa y sobre lo que la gente piensa, de tal forma que se supere la interpretación, y se genere una nueva conceptualización. Por último, la propuesta implica, radicalizar la experimentación no sólo en cuanto al trabajo de campo que se pueda hacer, sino que implica también experimentar el alcance de un concepto o de lo que una teoría puede ser; transformando la reflexividad crítica en creatividad conceptual (Descola, 2013; Latour, 2013; Viveiros de Castro, 2004a, 2009b, 2013c; Wagner, 1972a, 1981b).

Respecto de la epistemología del paradigma indígena de investigación, apuntaría a involucrar el sistema de conocimiento indígena en la investigación como un organizador del proceso de conocimiento (Wilson, 2008), es decir, la "única verdad" demostrada por la ciencia hegemónica pretende ser disputada (Berreman 1981; De Souza Santos, 2005; Díaz Polanco, 2006) por un sistema de pensamiento indígena con una propia lógica de conocimiento. Una lógica, cuyo vínculo comunicativo opere en las esferas de las relaciones de los seres vivos, de los espíritus y de los objetos físicos (Fernández Larrinoa, 2016). De allí la necesidad de que la epistemología en general, reconozca la diversidad de saberes, ya que el investigador debe ser parte de la lengua, el saber ancestral y la colectividad del conocimiento porque este y su producción serán medios de preservación de los conocimientos anidados al lugar, a la identidad y al principio cósmico. El conocimiento indígena producido será el que pervive en las leyendas, símbolos, tejidos, danzas, pinturas, rituales y ceremonias, y en la lengua, pues exige persista su herencia cultural. De modo que el conocimiento indígena toma distancia del occidental porque este último es una matriz cognitiva universal, donde el conocimiento para serlo, debe ser considerado válido, legítimo y objetivo (Chilisa, 2012; Kovach, 2010; Wilson, 2008).

El pensamiento indígena se sustenta en la cultura de sus colectivos, donde es necesario la aplicación del conocimiento dentro del "sistema de reciprocidad entre humanos, espíritus y objetos físicos" (Fernández Larrinoa, 2016), es decir, dentro de las garantías que la mirada 
indígena provee de respeto, ética, contingencia y beneficio colectivo (Porsanger, 2004). Según Chilisa, (2012), una metodología receptiva del pensamiento indígena, debe enlazar los "marcos teóricos, literatura y práctica de investigación; el sistema de valores y principios éticos; y los supuestos sobre la naturaleza de la realidad y el conocimiento". Asimismo, deben situarse en la investigación cualitativa (Kovach, 2010), ya que las formas de recabar información, se hace mediante la observación, la exploración, la reconceptualización y el diálogo; la cuales son sistemáticas y coherente con el conocimiento acumulado por generaciones al servicio del Buen Vivir. La experimentación que puede ser a través de la ceremonia, el ritual o las visiones sobre el territorio en la experiencia física y metafísica. La creación de modelos que están contenidos en "símbolos, círculos, figuras geométricas, canciones, bailes, historias, proverbios o metáforas". La visión espiritual que no separa el lenguaje racional y el metafórico. Y la interpretación de los fenómenos en el lugar, cuya explicación se alcanza por medio del lenguaje metafórico, las historias, y las imágenes (Arevalo \& Robles, 2013).

Los trabajos concretos de Nahuelpan (2007; 2013); Canales (2014); y Tzul Tzul (2015) entre otros, son ejemplos claros de esta experimentación desde el conocimiento indígena. Nahuelpan, en su trabajo desde los Mapuche, argumenta el cambio necesario en torno a la construcción del "indio" en la investigación social, pasando de ser objeto de estudio, a sujeto crítico de las formaciones ideológicas y epistemológicas hegemónicas capaz de desmantelar las jerarquías socio-raciales, políticas que soportan el colonialismo académico. En ese camino, por ejemplo, presenta como las historias mapuches se desarrollan en complejas interacciones sociales de hombres y mujeres en espacios cotidianos y de sus experiencias constitutivas de las historias familiares; resaltando que el "verdadero" kimün (conocimiento mapuche) es una diversidad de procesos particulares y contradictorios que han transitado por la memoria y la lucha, desafiando la historia oficial chilena desde lo heterogéneo y lo intergeneracional. Canales, por su parte; reconoce como punto de partida en el debate del pensamiento indígena actual, la descolonización como eje teórico en el siglo XX, pero recuerda la intensa y larga lucha que por siglos han librado los pueblos ancestrales en defensa de su conocimiento, códigos de sabiduría, memoria y prácticas. Para Canales, la radicalización de dicho proceso, pasa por el cuestionamiento de la asimilación y absorción étnico-cultural del indigenismo estatal y académico; creando territorios epistemológicos propios que produzcan conocimientos sobre la naturaleza y la sociedad desde los saberes ancestrales y comunitarios reflejados en su lógica y en su lengua. Finalmente, el trabajo de Tzul Tzul enfatiza no sólo en la propuesta de una epistemología indígena, sino en el aporte que a la misma han hecho las mujeres indígenas desde sus luchas y resistencias, desde la lucha dentro de la lucha; inscritas en tres dinámicas, las mujeres indígenas hacen parte del trabajo comunal, del uso de la tierra comunal, y de la producción comunal de la tierra, de tal modo que la decisión colectiva está sujeta a unos mecanismos que representan balances de poder. Enfocada en el trabajo en torno a los guipiles, Tzul Tzul, destaca que dichos textiles constituyen uno de los lugares desde donde se han fijado imágenes, ideas, historias y escrituras del pensamiento mesoamericano; en el guipil la mujer indígena exhibe, renueva, resignifica, y promueve los vínculos solidarios, la 
confianza, la reparación, la alegría, el gozo y la sanación del quehacer político indígena y en femenino.

Por todo lo anterior, los principios éticos del paradigma indígena son contextuales y relacionales, es decir, no solo tienen en cuenta a la persona sino al todo; y procuran que su asunto sea la colonialidad. Por tanto, los protocolos de investigación deben asumir responsabilidades del investigador y de la investigación en la tradición, basándose en los principios de respeto, de consentimiento informado, de privacidad y confidencialidad, de suficiencia de la investigación que requiere el reconocimiento de la comunidad, y de la sensibilidad social y cultural (Smith, 1999).

\section{Conclusiones}

Es evidente que la historia de la ciencia ha silenciado a los subalternos, no obstante, la convivencia de la teoría política-sociológica dentro del corpus de investigación (Spivak, 2011) y la ciencia nativa, potencializan el paradigma de investigación decolonial como instrumento de poder contra la colonialidad.

Este tipo de investigación (Haber, 2011; Gigena, 2012), con sus metodologías decoloniales, favorecen abordajes cualitativos de investigación de índole intercultural, extendida y colectiva, cuya subalternidad contribuye a la desnaturalización del experto y de la ciencia hegemónica que no le interesan los consensos, no escucha las distintas voces de los investigados (Briones, 2007)e ignora la propuesta de una metodología política desde la academia y desde los colectivos (Díaz, 2012). De modo que es claro que los estados y la sociedad son los que requieren interculturalidad, por ello, la investigación decolonial se plantea desde la comunidad, con el objeto de deconstruir los discursos hegemónicos monoculturales sobre la identidad y la cultura, y se plantea en detrimento de una absurda interseccionalidad entre etnicidad, género, orientación sexual, edad, religión y nacionalidad que apuesta por un escenario subalterno más desigual.

Cabe afirmar que las razones para radicalizar la epistemología decolonial, hacia formas de investigación desde el paradigma indígena, subyace en las consecuencias históricas y a veces indistinguibles de la colonialidad en los pueblos indígenas, y en los fundamentos filosóficos basados en los conocimientos indígenas, las teorías críticas, feministas, neomarxistas y los discursos poscoloniales. Este desafío promueve una realidad plural, socialmente construida y abre un espacio a la conexión de lo inmaterial y espiritual, cuyos valores dentro del proceso de investigación residen en el respeto por los saberes y practicas indígenas a partir de una responsabilidad relacional. Este paradigma aboga por la profundización de enfoques participativos y transformadores que van desde el sistema de conocimiento indígena y la oralidad histórica hasta las técnicas ajustadas de los paradigmas positivistas, interpretativos y critico-social; especialmente historiografías, estudios de caso, pensamiento crítico acerca del sujeto subalterno, revisiones y análisis teóricos. Por ello resulta importante que estos contenidos se incorporen a las mallas curriculares, a las asesorías de investigación y a las alianzas con centros, organizaciones e instituciones de 
investigación; todo ello en aras de desencarnar la lógica de uso del conocimiento y de producción de subjetividades de las universidades, la cual abraza el modelo de la modernidad universal como andamiaje político y cultural de la colonialidad.

Finalmente, se debe destacar el rol de la mujer, de los mayores o sabios como bastión de las historias, las ceremonias, los sueños, la meditación, las visiones y los rituales en las que perviven el conocimiento, la sabiduría y la experiencia indígena, ya que representan la cultura de la comunicación. La oralidad como medio de esta cultura de comunicación renueva las relaciones, fomenta la participación creativa con la naturaleza y educa sobre la responsabilidad armónica con el universo. De modo que los mayores permiten que sean tanto las ceremonias y los rituales como los sueños y las visiones, las técnicas para acceder al conocimiento relacional de lo material e inmaterial. Lo que implica un compromiso y una transformación epistemológica hacia el dialogo horizontal de saberes (De Souza Santos, 2009) desde la academia y desde los procesos de investigación especializada; ya que no se trata sólo de generar conocimiento científicamente valido, sino que se trata de generar un conocimiento comunitario y alterno desde otros complejos de veracidad, junto a otras ontologías y formas de pensar el mundo.

\section{Referencias}

Acosta, A., y Martínez, E. (2009). El Buen Vivir. Una vía para el desarrollo. Quito, Ecuador: AbyaYala.

Arendt, H. (2004). Los Orígenes del Totalitarismo (pp. 407). México DF, México. Taurus.

Arévalo Robles, G.A. (2013). Reportando desde un frente decolonial: la emergencia del paradigma indígena de investigación. En: G.A. Arévalo Robles y I. Zabaleta Chaustre (Ed.) Luchas, experiencias y resistencia en la diversidad y la multiplicidad (Cuadernos de Trabajo \# 2). Bogotá, Colombia: MunduBerriak.

Asad, T. (1973). Anthropology and the colonial encounter. New York, United States of America: Humanities Press.

Ashcroft, B., Griffiths, G., Tiffin, H. (1995). The postcolonial studies reader. London, United Kingdom: Routledge.

Bauman, Z. (1998). Modernidad y Holocausto. Madrid, España: Sequitur, 4a. Ed.

Berreman, J. (1981). The Politics of Truth: Essays in Critical Anthropology. Madras, South Asia:Publishers.

Briones, C., Cañuqueo, L., Kropff, L., Leuman, M. (2007). Escenas del multiculturalismo neoliberal. Una proyección desde el Sur. En: A. Grimson. (Ed.), Cultura y neoliberalismo. (pp.265299). Buenos Aires, Argentina: Clacso.

Cajete, G. (1999). Native Science: Natural Laws of Interdependence. Nuevo México, United States of America: Clear Light Publishers.

Canales Tapia, P. (2014). Intelectualidad indígena en américa latina: debates de descolonializacion, 1980-2010. Universum (Talca), 29(2), 49-64. 
Cajigas Rotundo, J.C. (2007). La biocolonialidad del poder. Amazonía, biodiversidad y ecocapitalismo. En: S. Castro Gómez, y R. Grosfoguel. (Ed.), El giro decolonial: reflexiones para una diversidad epistémica más allá del capitalismo global (pp. 27- 43). Bogotá, Colombia: Siglo del Hombre Editores, UC, IESC, PUJ.

Castro Gómez, S. (2004). La hybris del punto cero. Ciencia, raza e ilustración en la nueva granada (1750-1816). (pp. 345). Bogotá, Colombia: Pontificia Universidad Javeriana/Instituto Pensar.

Castro Gómez, S., y Grosfoguel, R. (2007). El giro decolonial: reflexiones para una diversidad epistémica más alládel capitalismo global. Bogotá: Siglo del Hombre Editores, UC, IESC, PUJ.

Chilisa, B. (2012). Indigenous Research Methodologies. London, United Kingdom: SAGE.

Descola, P. (2013). Beyond Nature and Culture, Chicago, UnitedStates of America: University of Chicago Press.

De Souza Santos, B. (2005). El milenio huérfano. Ensayos para una nueva cultura política. Madrid, España y Bogotá, Colombia: Editorial Trotta S.A. e ILSA.

De Sousa Santos, B. (2009). Una epistemología del sur: la reinvención del conocimiento y la emancipación social (pp. 368). México D.F, México: Consejo Latinoamericano de Ciencias Sociales/ Siglo XXI.

Díaz, R., y Rodríguez De Anca, A. (2012). Activismo intercultural: Una mirada descolonizadora, crítica e interseccional. Santiago de Chile, Chile: Mimeo.

Díaz Polanco, H. (2006). Elogio de la diversidad. Globalización, multiculturalismo y etnofagia. México, D.F, México: Siglo XXI Editores y El Colegio deSonora.

Engels, F. (1992). El origen de la familia, la propiedad privada y el Estado. (pp.176). Barcelona, España: Editorial Planeta.

Escobar, A. (1998). La invención del Tercer Mundo. Construcción y deconstrucción del desarrollo. Bogotá, Colombia: Editorial Norma.

Escobar, A. (2014). Sentipensar con la tierra. Nuevas lecturas sobre desarrollo, territorio y diferencia (pp. 184). Medellín, Colombia: Ediciones UNAULA, (Colección Pensamiento vivo).

Fals Borda, O. (2009). Una sociología sentipensante para América Latina. Víctor Manuel Moncayo Compilador (pp. 492). Bogotá, Colombia: Siglo del Hombre Editores y CLACSO.

Fernández De Larrinoa, K. (2016). Paradigma de investigación y pueblos indígenas del primer mundo: crítica cultural del trabajo social.Revista Andaluza de Antropología, (10), pp. 54-78).

Ferro, M. (2005). El libro negro del colonialismo (siglos XVI al XIX: del exterminio al arrepentimiento). Madrid, España: La Esfera de los Libros.

Foucalt, M. (1993). Microfísica del poder (pp.200). Madrid, España: Ediciones La Piqueta.

Gigena, A. (2013). Entre las emergencias epistémicas y los adeudos metodológicos y empíricos. En: J.I.Piovani, III Encuentro Latinoamericano de Metodología de las Ciencias Sociales (ELMeCS), llevado a cabo en la Universidad de Manizales/ Universidad de Caldas, Manizales, Colombia. 
Gramsci, A. (1975). Quadernidal Carcere, Istituto Gramsci (pp. 37-67). Roma, Italia: Cuaderno 1, \# 43.

Gray, M., Coates, J., Yellow Bird, M. (2008). Indigenous social work around the world: towards culturally relevant education and practice. Burlington, VT, USA: Aldershot: Ashgate.

Gray M.; Coates, J.; Yellow Bird, M.; Hetherington, T. (2013). Decolonizing social work. Burlington, VT, USA: Aldershot: Ashgate.

Grosfoguel, R. (2006). La descolonización de laeconomía política y los estudios postcoloniales: Transmodernidad, pensamiento fronterizo y colonialidad global. Tabula Rasa, (4), pp. 17-48.

Grosfoguel, R. (2007). Los dilemas de los estudios étnicos estadounidenses: multiculturalismo identitario, colonización disciplinaria y epistemologías decoloniales.Universitas humanística, (63), pp. 36-47.

Grupo De Estudios Sobre Colonialidad (GESCO). (2012). Estudios Decoloniales: Un panorama general. KULA: Antropólogos del Atlántico Sur (6), pp. 8-21.

Haber, A. (2011). Nometodología Payanesa: Notas de metodología indisciplinada. Revista Chilena de Antropología, (23), pp. 9-49.

Harper, K. (1986). Give me my father's body: the life of Minik, the New York Eskimo. Hanover, United States of America: Steerforth Press.

Hart, M.A. (2010). Indigenous worldviews, knowledges, and research: the development of an indigenous research paradigm. Journal of Indigenous Voices in Social Work, 1(1), pp. 1-16.

Hume, D. A (1967). Treatise of Human Nature. Oxford, United Kingdom: Oxford University Press.

Kovach, M. (2010). Indigenous Methodologies: Characteristics, Conversations, and Contexts. Toronto, Canada: University of Toronto Press.

Kuokkanen, R. (2000). Towards an indigenous paradigm from a Sami perspective. The Canadian Journal of Native Studies, 20 (2), pp. 411-436.

Laenui, P. (2000). Process of Decolonization. En M.Battiste (ed.), Reclaiming Indigenous Voice and Vision, Vancouver, Canada: UBC Press.

Lander, E. (2000). La colonialidad del saber: eurocentrismo y ciencias sociales. Perspectivas latinoamericanas. Buenos Aires, Argentina: CLACSO, Consejo Latinoamericano de Ciencias Sociales.

Lame, M.Q. (2004). Los pensamientos del indio que se educó dentro de las selvas colombianas.Popayán, Colombia: Universidad Del Cauca.

Latour, B. (2013). An inquiry into modes of existence. Cambridge, United States of America: Harvard University Press.

Lévy Bruhl, L. (2003). El alma primitiva. Barcelona, España: Península. 
Lévi Strauss, C. (1964). El pensamiento salvaje. México D.F, México: Fondo de Cultura Económica.

LéviStrauss, C. (1987). Antropología estructural. Barcelona, España: Península.

Leyva, X., ySpeed, S. (2008). Hacia la investigación descolonizada: nuestra experiencia de colabor. En: X. Leyva, A. Burguete, y S.Speed. (Ed.), Experiencias indígenas desde América Latina. Hacia la investigación decolabor. (pp. 34-59). México D.F., México: CIESAS, FLACSO Ecuador y FLACSO Guatemala.

Maldonado Torres, N. (2007). Sobre la colonialidad del ser: contribuciones al desarrollo de un concepto. En: S. Castro Gómez y R. Grosfoguel. (Ed.), El giro Decolonial. Reflexiones para una diversidad epistémica más allá del capitalismo global. (pp. 127-167). Bogotá, Colombia: Pontificia Universidad Javeriana - SigloDel Hombre.

Martin, K., \&Mirraboopa, B. (2003). Ways of knowing, being and doing: A theoretical framework and methods for indigenous and indigenist research. Journal of Australian Studies, 27 (76), pp. 203214

Mezzadra, S. (2008). Estudios postcoloniales: ensayosfundamentales. Madrid, España: Mapas.

Mignolo, W. (2007). Coloniality of power and de-colonial thinking. Cultural Studies (21), pp. 155167.

Nahuelpán Moreno, H.J. (2013). El lugar del “indio" en la investigación social. Reflexiones en torno a un debate político y epistémico aún pendiente. Revista Austral de Ciencias Sociales, (24), pp. 71-91.

Nahuelpán Moreno, H.J. (2014). Las 'zonas grises' de las historias mapuche. Colonialismo internalizado, marginalidad y políticas de la memoria. Revista de Historia Social y de las Mentalidades, 17(1), pp. 11-33.

Piñacué, J.C. (2014). Pensamiento indígena, tensiones y academia. Tabula Rasa, (20), pp. 161-192.

Porsanger, J. (2004). An Essay about Indigenous Methodology. Nordlit. Arbeidstidsskriftilitteratur. 8 (1), pp. 105-119.

Quijano, A. (2000). Colonialidad del poder y clasificación social. Journal of WorldSystemResearch, (6), 342-386.

Quijano, A. (2007). Colonialidad del poder y clasificación social. En: S. Castro-Gómez y R. Grosfoguel. (Eds.), El giro Decolonial. Reflexiones para una diversidad epistémica más allá del capitalismo global (pp. 93-126). Bogotá, Colombia:Pontificia Universidad Javeriana / SigloDel Hombre.

Renee, L. (2007). Can You Hear us Now? Voices from the Margin: Using Indigenous Methodologies in Geographic Research. Geographical Research, 45(2), pp. 130-139.

Sikes, P. (2006). Decolonizing research and methodologies: indigenous peoples and cross-cultural contexts. Pedagogy, Culture and Society, 14(3), pp. 349-358. 
Simpson, L. B. (2000). Anishinaabe ways of knowning. En J. Oakes, R. Riew, S. Koolage, L. Simpson y N. Schuster. (Eds.), Aboriginal health, identity and resources (pp. 165-185). Winnipeg, Manitoba: Native Studies Press.

Smith, L. (1999). Decolonizing Methodologies: Research and Indigenous Peoples. London, United Kingdom: ZedBooks.

Spivak, G.C. (2011) ¿Puede hablar el subalterno? Buenos Aires, Argentina: El cuenco de plata.

Stocking, G. W. Jr. (1974). Part X: Anthropology and society. En: F. Boas. (Ed.), The shaping of American anthropology, 1883-1911(pp. 307-340). Chicago, United States of America: TheUniversity of Chicago Press.

Trouillot, M.R. (2011). Transformaciones globales, la antropología y el mundo moderno (traducción de Cristóbal Gnecco). Popayán, Colombia: Universidad del Cauca, CESO, Universidad de Los Andes.

Tzul Tzul, G. (2015). Mujeres indígenas: Historias de la reproducción de la vida en Guatemala. Una reflexión a partir de la visita de Silvia Federici. Bajo el Volcán, 15 (22), 91-99

Vasco, L.G. (2003). Notas de viaje. Acerca de Marx y la Antropología. Bogotá, Colombia: Editorial Gente Nueva y Universidad del Magdalena.

Viveiros De Castro, E. (2004). Perspectival Anthropology and the Method of Controlled Equivocation.Tipiti: Journal of the Society for the Anthropology of Lowland South America, 2 (1), pp. 3-22.

Viveiros De Castro, E. (2009).Métaphysiquescannibales, París, La France: PressesUniversitaires de France.

Viveiros De Castro, E. (2013). The Relative Native. HAU: Journal of Ethnographic Theory, 3 (3), pp. 473-502.

Wagner, R. (1972). Habu: The Innovation of Meaning in Daribi Religion, Chicago, USA \& London, United Kingdom: University of Chicago Press.

Wagner, R. (1981) The Invention of Culture. Chicago, USA: University of Chicago Press.

Walsh, C. (2007) ¿Son posibles unas ciencias sociales/culturales otras? Reflexiones en torno a las epistemologías decoloniales. Revista Nómadas, (26), pp. 102-113.

Walsh, C. (2009). Interculturalidad, plurinacionalidad y razón decolonial: Refundares políticoepistémicos en marcha. En: S. Albagli, \& M.L. Maciel. (Ed.), Conocimiento, capital y desarrollo: dialécticas contemporáneas. Buenos Aires, Argentina: Editora La Crujía.

Wilson, S. (2008). Research Is Ceremony: Indigenous Research Methods. Nova Scotia, Canada: Fernwood Publishing.

Wolf, E. (1987). Europa y la gente sin historia. México D.F, México: Fondo de Cultura Económica. 